\title{
Processo decisório na agricultura familiar: o caso da Coopasvale, Rio Grande do Sul, Brasil ${ }^{*}$
}

\author{
Lavínia Lopes de Mello \\ Luis Carlos Alves da Silva ${ }^{2}$ \\ Fernando Batista Bandeira da Fontoura ${ }^{3}$ \\ Cidonea Machado Deponti ${ }^{4}$ \\ Maicon da Silva ${ }^{5}$
}

\begin{abstract}
Resumo
O presente estudo tem por objetivo identificar os fatores que influenciam o processo de tomada de decisão na gestão dos agricultores associados da Coopasvale-RS. Neste sentido, o conteúdo agrega possibilidades significativas para o desenvolvimento regional à medida que a agricultura familiar possui papel importante na economia brasileira. Metodologicamente a pesquisa caracteriza-se como bibliográfica e descritiva, com dados analisados qualitativamente. Como principais resultados da pesquisa destacam-se que, $86 \%$ dos associados da Coopasvale não têm dificuldade para definir qual cultivar será produzido em sua propriedade, essa escolha em $57 \%$ dos casos está associada a fatores econômicos. Já com relação a aplicação de controles econômicos e financeiros, apenas $14 \%$ dos participantes da pesquisa aplicam esse tipo de controle. Dessa forma, conclui-se que, desempenhar uma boa administração, com organização e planejamento eficientes, para alcançar produtividade na agricultura familiar, apresenta-se como algo complexo e um desafio para os produtores rurais e que processo decisório nas propriedades objeto do estudo estão associados a fatores econômicos.
\end{abstract}

Palavras-Chave: Desenvolvimento Regional. Propriedade Rural. Agricultura. Gestão Rural.

\section{Decision-making process in Family agriculture: the case of Coopasvale, Rio Grande do Sul, Brazil}

\begin{abstract}
This study aims to identify the factors that influence the decision-making process in the management of Coopasvale's associated farmers. In this sense, the content adds significant possibilities for regional development, as family farming plays an important role in the economy. Methodologically the research is characterized as bibliographic and descriptive, with data analyzed qualitatively. As the main results of the research stand out that $86 \%$ of Coopasvale associates have no difficulty in defining which cultivar will be produced on their property, this choice in $57 \%$ of cases is associated with economic factors. Regarding the application of economic and financial controls, only $14 \%$ of the survey participants apply this type of control. Thus, it can be concluded that, performing a good administration, with efficient organization and planning, to achieve productivity in family farming, presents itself as something complex and a challenge for rural producers and that the decision process in the properties object of the study are associated with economic factors.
\end{abstract}

Keywords: Regional Development. Rural Property. Agriculture. Rural Management.

*Este artigo foi avaliado e apresentado no evento II-SLAEDR/VI-SIDER/III-SIDETEG, da UNIJUÍ, e indicado e aceito para ser publicado nesta revista pelo sistema Fast-Track.

${ }^{1}$ Mestranda no Programa de Pós-Graduação em Desenvolvimento Regional (UNISC). Bolsista CAPES. Email: lavinia97lopes@hotmail.com

${ }^{2}$ Mestre em Administração (UNISC). Email: luiscarlosalves0207@gmail.com

${ }^{3}$ Doutorado em Desenvolvimento Regional (UNISC). Professor do Programa de Pós-Graduação em Desenvolvimento Regional da Universidade de Santa Cruz do Sul-RS (UNISC). Email: fbfontoura@unisc.br

${ }^{4}$ Doutorado em Desenvolvimento Rural (UFRGS). Professora do Programa de Pós-Graduação em Desenvolvimento Regional da Universidade de Santa Cruz do Sul-RS (UNISC). Email: cidonea@unisc.br

${ }^{5}$ Mestre em Administração (UNISC). Email: maicon213@bol.com.br 


\section{Introdução}

Os princípios da multifuncionalidade da agricultura familiar destacam a produção em moldes sustentáveis, a segurança alimentar e a reprodução socioeconômica dos agricultores familiares como balizadores de um novo paradigma produtivo diferente do agronegócio, fortalecendo os sistemas cooperativos locais e sustentáveis de produção, bem como desenvolvido com base nas territorialidades.

Conforme publicado no site da Nações Unidas, no ano de 2019 a agricultura familiar (espalhada por todo o planeta com uma rede de 500 milhões de propriedades) é responsável por cerca de $50 \%$ a $80 \%$ do comércio in natura de alimentos e conjuntamente, colabora para a expansão da sustentabilidade ambiental da agricultura através da preservação e da recuperação da biodiversidade de ecossistemas. Além disso, proporciona o abastecimento com alimentos tradicionais e nutritivos viabilizando uma dieta equilibrada, conservando o patrimônio cultural na zona rural (ONU, 2019). No Brasil, 70\% dos alimentos consumidos são produzidos na agricultura familiar destacando sua importância no sentido amplo de desenvolvimento (CAMPOS e VILLAR, 2019).

Nesse contexto, a agricultura familiar é considerada como uma das bases sobre as quais se construiu o desenvolvimento, que marca as nações mais desenvolvidas, sendo colocada no centro das estratégias de desenvolvimento regional. Na ótica de Karnopp (2012), desenvolvimento regional é um processo de mudança estrutural localizado, determinado por três principais pilares: progresso da própria região, progresso da comunidade ou sociedade que a habita e desenvolvimento de cada indivíduo pertencente à referida sociedade.

No Brasil, até poucas décadas, esse processo era o inverso, devido à grande dificuldade que os agentes de desenvolvimento regional encontravam para interagir com o meio rural. Isso em razão da falta de percepção sobre a realidade dos distintos grupos de agricultores que compõem cada região, revelando o desconhecimento das especificidades que os diferenciam uns dos outros.

A partir dessa análise, entender a importância da aplicação de controles econômicos e financeiros na agricultura familiar, passa a ser uma alternativa para surgimento de sistemas de organização da produção em uma sociedade em que o modelo taylorista e fordista já apresenta sinais de declínio, conforme descrito por Tenório $(1998 ; 2011)$ sendo que a gestão massificada dá espaço para novas formações sociais e organizacionais com viés para a diversidade (ETGES; DEGRANDI, 2013; SANTOS, 1982). 
Dada a relevância do tema, foram buscados na literatura estudos correlatos que enfatizam a importância da pesquisa em questão. Podem ser destacados, na literatura nacional, os estudos de Durán e Wives (2018), intitulado como "Tomada de decisão e agricultura: uma revisão recente sobre agricultura orgânica", elaborado por meio de estudos que utilizaram análise geral, estatística descritiva e estatística inferencial/métodos matemáticos. Da Rosa, Caumo, Machado e Staduto (2018) também pesquisaram a agricultura orgânica através da aplicação de questionários semiestruturados junto aos produtores, trazendo concepções sobre a tomada de decisão, com o artigo "Fatores influentes no processo decisório de agricultores de produtos orgânicos". O estudo descritivo de Oliveira (2007), chamado A informação como instrumento para tomada de decisão do agricultor de Giruá no Estado do Rio Grande do Sul Brasil, aborda uma compreensão mais ampla desse processo de gestão das propriedades rurais, que é insuficientemente tratado na literatura, pois não se compreende a propriedade como um todo, uma vez que os trabalhos existentes nessa área estão mais restritos aos aspectos econômicos (OLIVEIRA, 2007).

Diante da complexidade multidimensional que envolve o processo de tomada de decisão na agricultura familiar, este estudo objetiva identificar os fatores que influenciam o processo da tomada de decisão, na gestão dos agricultores associados da Coopasvale-RS. Nesse contexto, questiona-se: Como ocorre o processo de tomada de decisão, no tocante a gestão rural pelos associados da Coopasvale-RS, em contextos de desenvolvimento organizacional e regional?

O presente estudo justifica-se, a partir do momento que agricultura familiar está inserida em um contexto social, no que se refere a questões econômicas e de autonomia cultural e, também, como forma de diversificação da produção regional, buscando proporcionar maior clareza e riqueza ao tema. Entender seu processo histórico e sua dinâmica tornam-se importantes para seu desenvolvimento. Nesse contexto, o planejamento das atividades na agricultura familiar, pode ser considerado como um dos primeiros passos para auxiliar o produtor rural no seu processo decisório, entender como acontece esse processo é primeiro passo para desenvolvimento regional multidimensional.

O presente artigo divide-se em quatro seções. Na primeira, discute-se a teoria das decisões, tomada de decisão na agricultura familiar, processos gerenciais na agricultura familiar e a importância dos fatores econômicos e financeiros na agricultura familiar. Na segunda, apresenta-se materiais e métodos utilizados na pesquisa. A terceira trata da análise dos resultados. Finalmente, na última, apresentam-se as considerações finais. 


\section{Teoria das decisões}

A Teoria das Decisões foi desenvolvida pelo economista estadunidense Herbert Alexander Simon (1916-2001), o qual realizou uma extensa produção acadêmica ao longo de sua vida, sua teoria construída a partir da década de 1940 discorre sobre a decisão econômica em volta da ótica de racionalidade limitada. Até aquele tempo, a ideia de racionalidade era entendida como absoluta e perfeita, e, por conseguinte adviria uma diligência pela eficiência perfeita no cenário administrativo (SBICCA, 2014; DE OLIVEIRA e DE PAULA, 2014).

Nesse sentido, os autores Steingraber e Fernandez (2013) caracterizam a pesquisa de Simon como "um divisor de águas na teoria econômica", no ano de 1978 o economista é contemplado com o Prêmio Nobel de Economia em virtude de seus estudos acerca do processo decisório organizacional, entre meados dos anos setenta e oitenta a discussão relativa à racionalidade atinge novas concepções (STEINGRABER e FERNANDEZ, 2013; SBICCA, 2014). surgimento da Teoria das Decisões é relativamente adverso à racionalidade neoclássica de comportamento maximizador, segundo Steingraber e Fernandez (2013, p.126):

A exposição de Simon nas demais teorias heterodoxas foi validada pela sua notoriedade como Nobel de Economia, mas também como forma de diferenciação da racionalidade neoclássica e da teoria das expectativas racionais que ganhou força na década de 80. A racionalidade limitada foi cunhada como uma alternativa à racionalidade substantiva neoclássica, mas tornou-se um dos pressupostos das teorias heterodoxas que buscavam se diferenciarem justamente da vertente neoclássica.

De acordo com Simon a maximização faz-se inexecutável em consequência da impossibilidade lógica, dado que, se isso fosse verídico, antes de tomar uma decisão as pessoas deveriam ser capazes de examinar todas as alternativas possíveis. Dessa forma, mesmo que se acredite que se maximiza, na verdade se contemporiza, a conotação de maximização pode até prevalecer. Entretanto, não existe segurança de que ela aconteça, pois sempre há a chance de surgimento de outras possibilidades de tomada de decisão causadoras de um resultado mais favorável (DE OLIVEIRA e DE PAULA, 2014).

$\mathrm{Na}$ pesquisa precursora do economista são consideradas três fases no processo de tomar decisões: prospecção (análise de um problema ou situação que requer solução), concepção (criação de alternativas de solução para o problema ou situação) e decisão (julgamento e escolha de uma das alternativas propostas). Conforme Simon há uma busca de maximização dos ganhos pelo "homem econômico", através da racionalidade, que, de acordo com ele é limitada e ineficiente (SALES, 2020). 
A caracterização de racionalidade limitada é traçada pela forma em que é desempenhado o processo de tomada de decisão pelas pessoas. Segundo o economista, determina-se uma classificação das informações que podem ser relevantes, sem ser executada uma análise de todos os dados acessíveis. Simon concluiu que o ser humano se utiliza de atalhos intitulados por ele de heurísticas, para realizar a tomada de decisão e enfrentar os obstáculos da vida real, como processos de observação e de definição da pesquisa por alternativas de escolha (SIMON, 1990, apud SBICCA, 2014).

Sbicca (2014) descreve um exemplo prático da heurística na ótica da teoria de Herbert Simon: no processo de solução de um problema é desenvolvida uma expectativa com o uso da experiência, no momento em que uma opção analisada responde a essa expectativa é finalizado o processo de análise, o que pode ocasionar uma diminuição do número de alternativas pesquisadas. A autora salienta que essa prática simplifica a decisão nos casos em que o número de alternativas para ser avaliado é muito grande, outros inúmeros obstáculos podem ser eliminados com a utilização desses métodos, por exemplo, opções ilimitadas ou de consequências que atinjam um volume maior de pessoas.

Dessa forma, observa-se que a tomada de decisão, na perspectiva de Simon, possibilita compreender que a decisão é um processo complexo e envolve diversas variáveis que são condicionadas por diferentes motivos, tais como: econômicos, sociais, psicológicos, emocionais, culturais, etc. Na próxima seção serão discutidos alguns aspectos relacionados ao processo de tomada de decisão na agricultura familiar.

\subsection{Tomada de decisão na agricultura familiar}

O processo de tomada de decisão é de natureza lógica e circunstancial, podendo ocorrer no âmbito pessoal, familiar, social ou profissional do indivíduo. O exercício dessa função é conduzido pelo raciocínio lógico e racional, próprio da natureza humana. Independente das circunstâncias, da atividade exercida, as decisões são tomadas considerando várias questões que têm por fundamento um caráter eminentemente lógico-racional.

A lógica racional preocupa-se com os processos de seleção de alternativas de acordo com alguns sistemas de valores que permitem avaliar as consequências de cada comportamento. É a partir das alternativas disponíveis que o indivíduo, por meio da racionalidade limitada, analisa consequências futuras e realiza o processo decisório, buscando um resultado satisfatório (SIMON, 1972). 
Segundo Rambo e Machado (2009), Simon salienta que a tomada de decisão envolve uma racionalidade limitada e satisfatória, evidenciando que o comportamento humano está orientado por caminhos que levam à satisfação individual ou de um grupo, o que vai ao encontro não necessariamente da ideia de maximização do lucro, mas sim de outros elementos que não apenas uma racionalidade econômica. Assim, as decisões tomadas estão associadas a alternativas boas, que nem sempre são consideradas as melhores (SIMON, 1978).

A partir, do entendimento que as escolhas humanas são diretamente orientadas por uma racionalidade de satisfação das necessidades, seguindo prioridades e racionalidade próprias, ou seja, há uma multiplicidade de racionalidades, Simon (1978). Entender como acontece o processo de tomada de decisão do produtor rural na agricultura familiar é algo desafiador, a partir do momento em que esse processo pode estar associado, entre outros fatores, à experiência de vida, à maturidade, ao conhecimento, à percepção e à intuição. Nesse sentido, torna-se relevante entender os fatores que influenciam essa decisão.

Na visão de Beck (2012), a modernização reflexiva concebe a força motriz da reinvenção da modernidade e de seus efeitos colaterais (reflexividade), abrindo um leque de cenários para a evolução dos termos da modernização. Esses termos são percebidos, na agricultura familiar, a partir do momento em que o produtor rural faz uma reflexão multidimensional da sua atividade e começa a entender que o processo de tomada de decisão parte inicialmente de uma reflexão de todos os seus conceitos.

O fato de considerar que o produtor rural possui razões para agir à sua maneira implica procurar compreender essas razões, para que se possa trabalhar fontes de informação e estimular o desenvolvimento de políticas públicas que possibilitem ao produtor realizar melhor os processos de tomada de decisão na gestão da sua propriedade (OLIVEIRA, 2007, p. 18).

$\mathrm{Na}$ literatura, encontra-se a tese de doutorado de Ocaña (1996), que pesquisou os fatores que influenciam o processo decisório de produtores rurais da Espanha. $\mathrm{O}$ autor ressalta que as unidades de produção agrícola estão inseridas em um sistema por ele denominado de sistema de exploração agrícola, em que um conjunto de fatores interage e influencia o produtor rural em sua tomada de decisão. Mesmo diante das diferenças territoriais, culturais e espaciais da referida tese para o ensaio proposto, abre-se um debate contemporâneo para a busca de contribuições que ela pode trazer para o ensaio em questão.

Silveira (2016) destaca que, além de analisar os vínculos orgânicos e funcionais existentes entre a região e o espaço global, também é preciso entender a região propriamente dita no âmbito da escala intrarregional. Nesse contexto, pode-se aferir, de forma superficial, 
que algumas das decisões tomadas pelos produtores rurais de uma determina região, a ser analisada estão associadas a fatores econômicos, visto que o modelo de atividade exercida por eles, na maioria dos casos, está voltado para a exploração da atividade agrícola, sendo algo identificado com bastante fluidez no estudo realizado por Ocaña.

A partir desse entendimento, Ocaña, Vecino e Avilés (1998) afirmam que o produtor, como um indivíduo tomador de decisão na agricultura familiar, é o resultado da agregação de fatores socioeconômicos (idade, renda, escolaridade, informação, associativismo, entre outros) e psicológicos (valores). O produtor é o responsável por gerir uma área produtiva, bem como a estrutura de produção (maquinários, mão de obra, entre outros). Os critérios utilizados na gestão são o resultado da interação entre o indivíduo, a estrutura e o ambiente em que ele está inserido.

Dessa forma, tendo como foco entender como acontece o processo de tomada de decisão na agricultura familiar, passa a ser um desafio inerente para desenvolvimento regional das famílias que sobrevivem da produção de suas propriedades rurais.

\subsection{Processo de gestão rural na agricultura familiar}

A identificação de quais são as formas adequadas para que o produtor realize o gerenciamento de todos os custos da plantação de forma a atingir resultados melhores no momento da venda de seu produto, para obtenção de bons resultados, é um dos desafios na agricultura familiar. Buscando uma maior competitividade dos estabelecimentos rurais surge a necessidade da implementação de processos de gerenciamento que contemplem o mínimo possível de padrões para o registro de informações que servirão de apoio na tomada de decisão para produtor rural (DEPONTI 2014).

Callado, Albuquerque e Silva (2007, p. 57) dizem que "os gestores que atuam no âmbito da agricultura familiar devem ampliar seus conhecimentos utilizando programas de capacitação técnica e acompanhamento para poderem obter um melhor aproveitamento de sua produção".

Para o planejamento, controle e, também, tomada de decisões, é preciso analisar as informações contábeis do produtor rural "[...] a falta de planejamento e gestão de custos, pode fazer com que o produtor tenha prejuízos ou ainda não explore da melhor forma possível os lucros do seu trabalho". (FONSECA, 2018, p. 15). Na ótica de Fontoura (2013), a contabilidade de custos abrange os custos de maneira distinta, e assim contribui para a produção de informações variadas para qualquer atividade econômica. Para o monitoramento dos custos 
um aspecto relevante é o conhecimento das metodologias de custeio como o custeio variável, absorção, ABC, RKW, GECON, entre outros encontrados na literatura, porém neste estudo não serão abordadas essas metodologias visto que não são foco desta pesquisa (BORNIA, 2010; FONTOURA, 2013; MARTINS e ROCHA, 2015).

Classificar os custos corretamente é imprescindível na gestão de uma propriedade rural. Uma divisão equivocada resulta em dados errôneos sobre seu estado financeiro. Existem diversas fontes monetárias na agricultura familiar que complexificam o processo de previsão de renda. Conforme Pereira, Brito e Pereira (2017), os programas compensatórios, serviços, vendas, aposentadorias e pensões, assim como a difícil mensuração da produção para autoconsumo e a sazonalidade da produção, dificultam o processo de estimar valores finais.

Realizar a classificação dos custos torna-se uma das maiores dificuldades dos agricultores no processo de gerenciamento, por isso, é preciso buscar ajuda para desempenhar essa atividade (GURA, 2018). Uma possibilidade para auxiliar os agricultores na gestão de suas propriedades é a implantação de tecnologias de informação e de gestão que conforme destaca Deponti (2014, p.16) “podem contribuir de forma substancial para a gestão dos negócios das propriedades rurais familiares".

\footnotetext{
As tecnologias de informação e comunicação, (TICS), estão cada vez mais presentes na vida dos brasileiros e no meio rural. Estas novas tecnologias poderiam ser utilizadas para melhoria do acesso à informação na atividade rural. Principalmente, no que se refere às tecnologias básicas de gestão econômica e financeira, visando uma melhor visão da atividade desenvolvida pelos agricultores familiares. (FONTOURA e DEPONTI, 2018, p. 91).
}

O acesso à informação pelos brasileiros é cada vez mais usual. Entretanto, não são todas as famílias rurais que possuem acesso à internet, conforme a pesquisa TIC Domicílios divulgada no ano de 2018 de toda a zona rural 49\% está conectada (LAVADO, 2019). Além disso, há uma complexidade na utilização das tecnologias de informação e comunicação pelos produtores rurais no Brasil. Dado que a maioria dos agricultores possui baixa escolaridade e os seus sucessores geralmente param de estudar, por esse motivo, o acesso e uso de novas tecnologias para auxiliar no desempenho das atividades é dificultado (DEPONTI, 2014).

\section{Metodologia}

O presente estudo caracteriza-se como descritivo e bibliográfico, com os dados analisados qualitativamente. A pesquisa bibliográfica de acordo com Silva (2017, p. 148) é a 
explicação do tema baseando-se em fundamentos teóricos divulgados em livros, revistas, artigos científicos etc. Para alcançar à resposta do problema da pesquisa, foram usadas técnicas qualitativas por meio da coleta de dados apurados através da aplicação de questionários, bem como descritivas tendo como propósito descrever as características do plantio das culturas e processo decisório dos associados (SILVEIRA e CÓRDOVA, 2009).

A pesquisa foi desenvolvida na Cooperativa Agrícola - Coopasvale, fundada no ano de 2015, que conta com cinquenta e seis famílias associadas, perfil das propriedades tem em média cinco hectares, renda familiar gira em torno de um a três salários-mínimos por família, que são formadas em média por três pessoas. Os principais produtos comercializados pela cooperativa são: repolho, alface, tempero verde, couve e pepino, a comercialização dos produtos é realizada em programas institucionais como o Programa Nacional de Alimentação Escolar (PNAE) e o Programa de Aquisição de Alimentos (PAA) e, também, em mercados convencionais na região, principalmente supermercados. A cooperativa tem sua sede localizada na cidade de Passo do Sobrado-RS (Figura 1).

Figura 1: Localização do município de Passo do Sobrado-RS

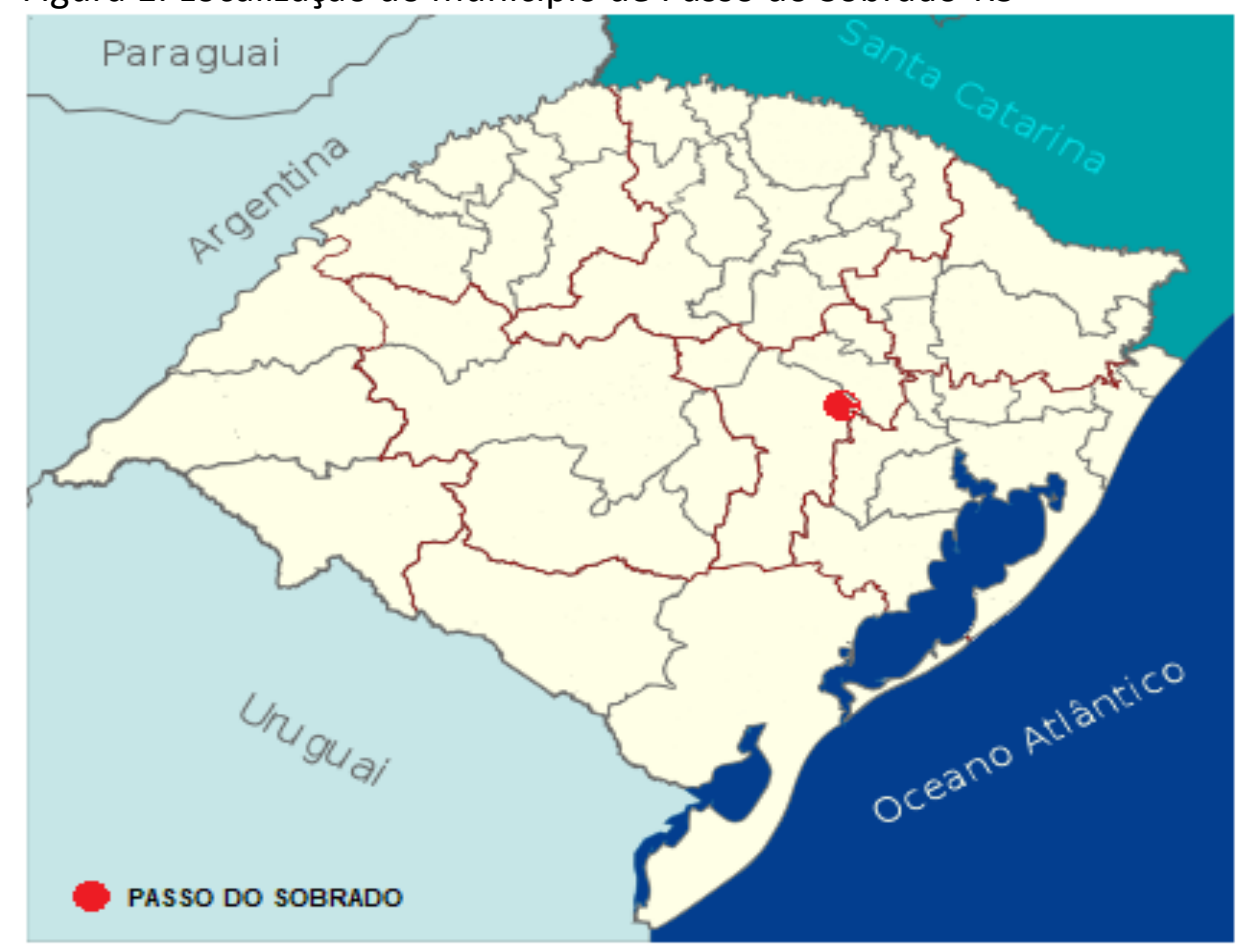

Fonte: Wikipedia - A enciclopédia livre

https://pt.wikipedia.org/wiki/Lista_de_regi\%C3\%B5es_geogr\%C3\%A1ficas_intermedi \%C3\%A1rias_e_imediatas_do_Rio_Grande_do_Sul). 
O município de Passo do Sobrado-RS tem aproximadamente mil e quinhentas propriedades rurais, sua economia está alicerçada na produção primária, tendo como destaque o cultivo de milho, arroz, soja, feijão, gado, peixe e fumo (IBGE, 2020).

A coleta de dados aconteceu de forma primária através da aplicação de um questionário, contendo seis perguntas objetivas, cada pergunta o respondente tinha quatro opções de resposta. O questionário foi enviado via e-mail para todos os associados.

Quadro 1: Questionário aplicado aos agricultores familiares associados da Coopasvale

\begin{tabular}{|c|}
\hline $\begin{array}{l}\text { 1) Há dificuldades para decidir o que produzir? } \\
\qquad \begin{array}{l}\square \text { Sim } \\
\square \text { Não }\end{array}\end{array}$ \\
\hline 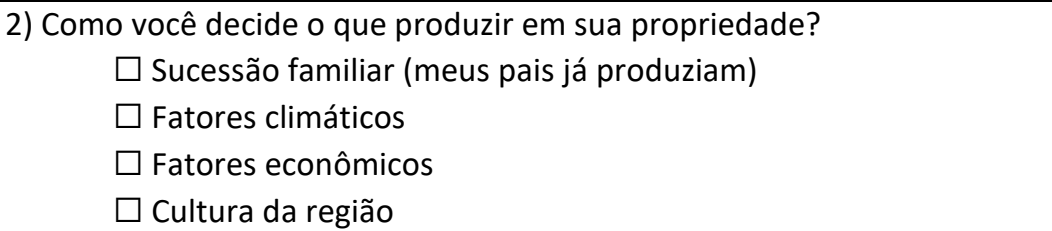 \\
\hline $\begin{array}{l}\text { 3) Como são definidas as quantidades a serem produzidas? } \\
\qquad \text { De acordo com a demanda } \\
\square \text { De acordo com a estação do ano } \\
\square \text { De acordo com a mão de obra } \\
\square \text { De acordo com a capacidade produtiva da propriedade }\end{array}$ \\
\hline $\begin{array}{l}\text { 4) Como são definidos os períodos de produção? } \\
\qquad \text { Demanda de mercado } \\
\square \text { Clima da região } \\
\square \text { De acordo com o cultivar plantado } \\
\square \text { Por questões culturais da região }\end{array}$ \\
\hline $\begin{array}{l}\text { 5) Quais os controles de atividade que são realizados na sua propriedade? } \\
\qquad \begin{array}{l}\square \text { Estoques } \\
\square \text { Controles contábeis } \\
\square \text { Controle de qualidade } \\
\square \text { Não faço nenhum controle }\end{array}\end{array}$ \\
\hline $\begin{array}{l}\text { 6) Onde são realizados os registros de atividades? } \\
\qquad \begin{array}{l}\square \text { Diário de campo } \\
\square \text { Planilha do Excel ou outro programa do computador } \\
\square \text { Guardo documentos (Notas Fiscais, etc.) } \\
\square \text { Não faço registros }\end{array}\end{array}$ \\
\hline
\end{tabular}

Fonte: Elaborado pelos autores da pesquisa (2020)

Análise dos dados foi realizada no Microsoft Excel, sendo que a apresentação destes aconteceu através de gráficos estatísticos, possibilitando a análise de como ocorre o processo de tomada de decisão dos agricultores associados da Coopasvale-RS. 


\section{Análise e discussão dos resultados}

Para análise dos resultados desse estudo, foram aplicados cinquenta e seis questionários, representando $100 \%$ dos cooperativados, dos quais foram respondidos trinta e quatro questionários $(60,7 \%)$ e vinte e dois questionários $(39,3 \%)$ não tiveram resposta. A amostra alcançada foi considerada probabilística com 90\% de confiança e $9 \%$ de erro.

Os resultados iniciais da pesquisa nos mostram que, $86 \%$ dos participantes, relataram que não têm dificuldades de decidir o que será cultivado e/ou produzido em sua propriedade. Esse alto percentual, pode estar alinhado a processos empregados em decisões não racionais, sendo definidas como estratégias que ignoram parte da informação com o objetivo de tornar a escolha mais fácil e rápida, Simon (1972), o mesmo autor conclui que o ser humano se utiliza de atalhos intitulados por ele de heurísticas, para realizar a tomada de decisão e enfrentar os obstáculos da vida real.

A partir dessa resposta, partiu-se para o gráfico 1, que apresenta uma condensação de como acontece o processo de escolha do que será cultivado e/ou produzido por estes produtores, considerando que a economia da região passa por um momento de instabilidade e as condições climáticas que castigam todos os produtores da região devido à falta de chuva, tornando assim esse processo cada vez mais complexo.

Gráfico 1: Critérios utilizados na decisão sobre o que será cultivado e/ou produzido

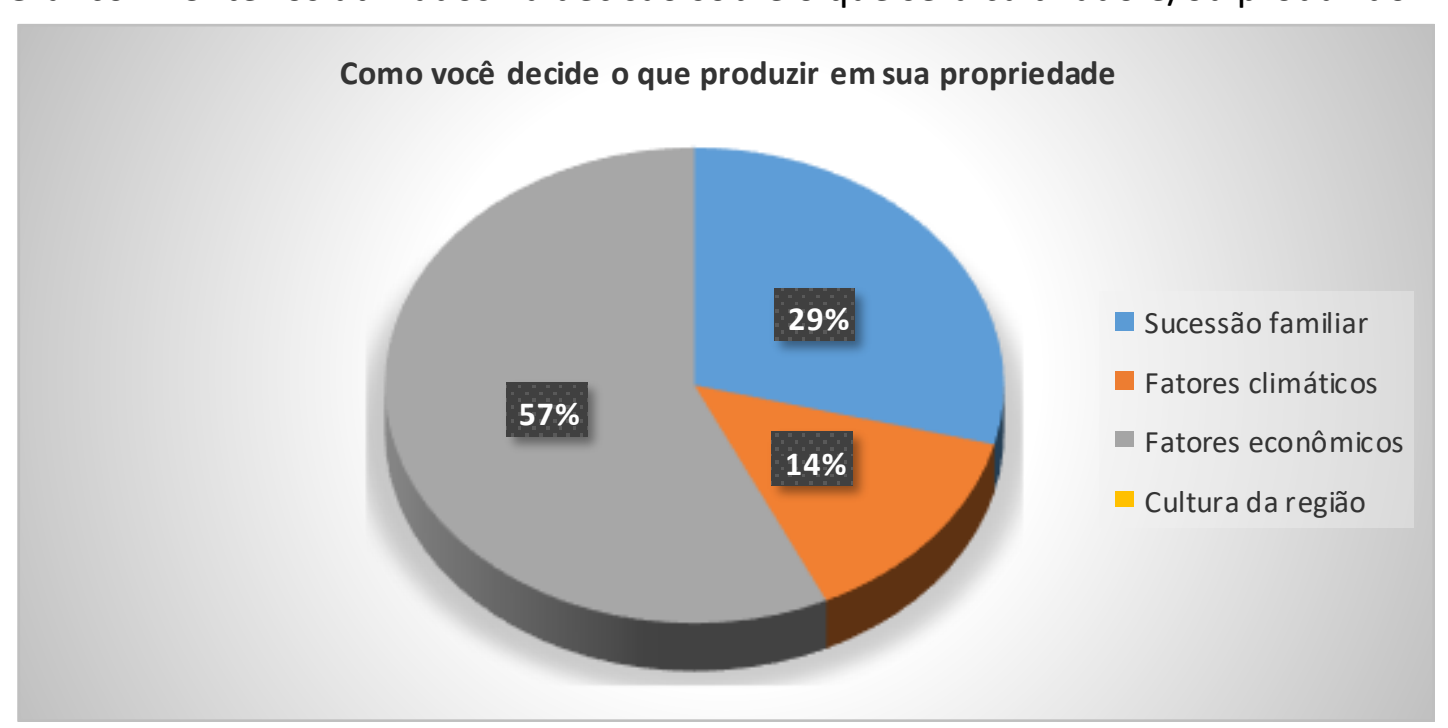

Fonte: Dados da pesquisa (2020)

Conforme apresentado no gráfico 1, 57\% dos agricultores participantes da pesquisa responderam que a decisão de qual cultivar deve ser produzido em sua propriedade está 
associada a fatores econômicos, estes são considerados em função do que acontece na região onde os agricultores residem. Nesse sentido, Ocaña (1996), destaca que as características socioeconômicas se apresentam como fundamento mais resolutivo no processo decisórios dos agricultores, mostrando traços de uma sociedade que tem capitalismo enraizado em sua cultura. Outros $29 \%$ dos entrevistados responderam que sua decisão de produção está associada à sucessão familiar e, outros $14 \%$ a fatores climáticos, já a questão relacionada à cultura da região não teve nem um agricultor que usasse esse fator.

Após apresentação de quais práticas são usadas, para escolha do cultivar a ser produzido, será apresentado no gráfico 2, quais indicadores são considerados, para a definição das quantidades as serem produzidas em cada propriedade.

Gráfico 2: Quantidades a serem produzidas

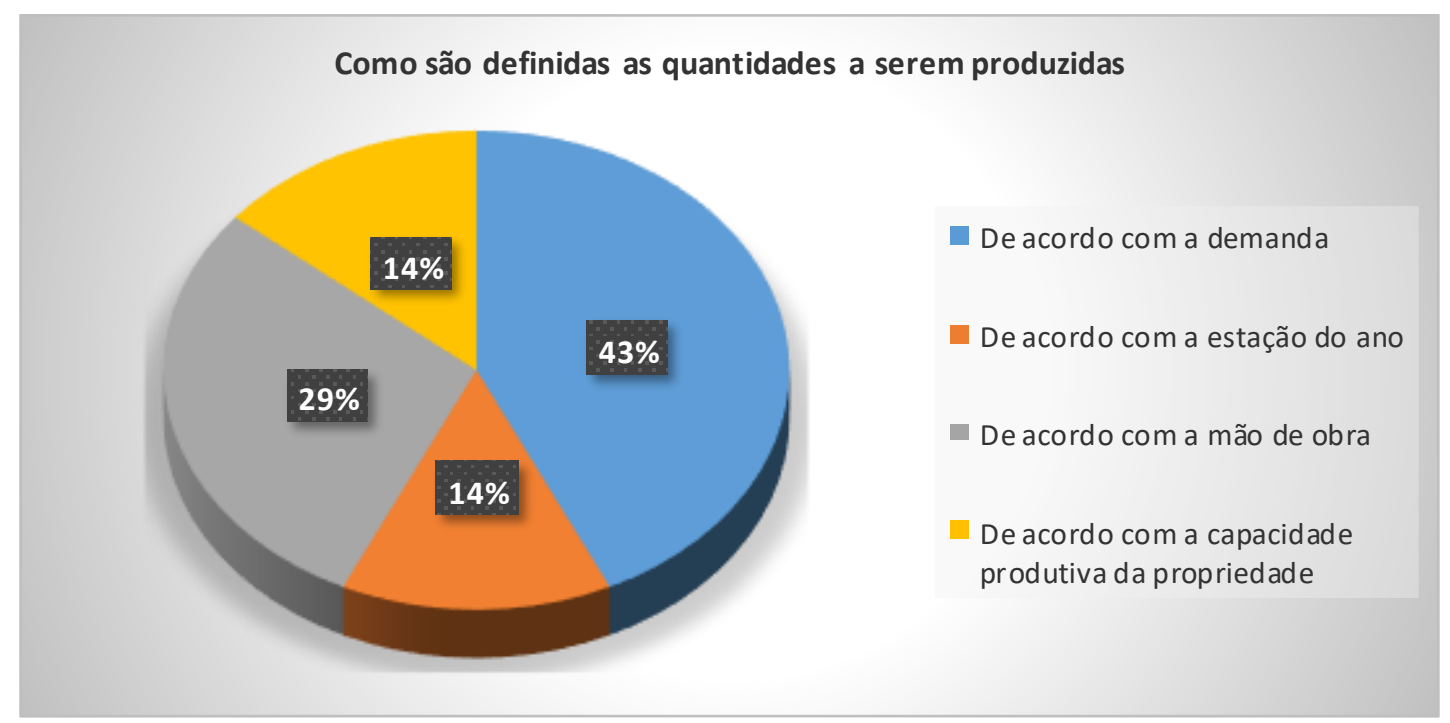

Fonte: Dados da pesquisa (2020)

As respostas apresentadas no gráfico 2 demonstram que processo de tomada de decisão dos agricultores, em relação as quantidades a serem produzidas, está associado à demanda (43\%). Nesse sentido, Crepaldi (1998), destaca que conhecer o mercado consumidor é elemento básico para o desenvolvimento da atividade rural, minimizando os riscos com relação a produção acabar não tendo mercado para sua comercialização. Já outros $29 \%$ dos entrevistados, produz conforme mão de obra disponível na propriedade.

Identificado, como acontece o processo de tomada de decisão para definição das quantidades a serem produzidas, partiu-se para a definição dos períodos de produção, conforme apresentados no gráfico 3. 
Gráfico 3: Definição dos períodos de produção

Como são definidos os períodos de produção

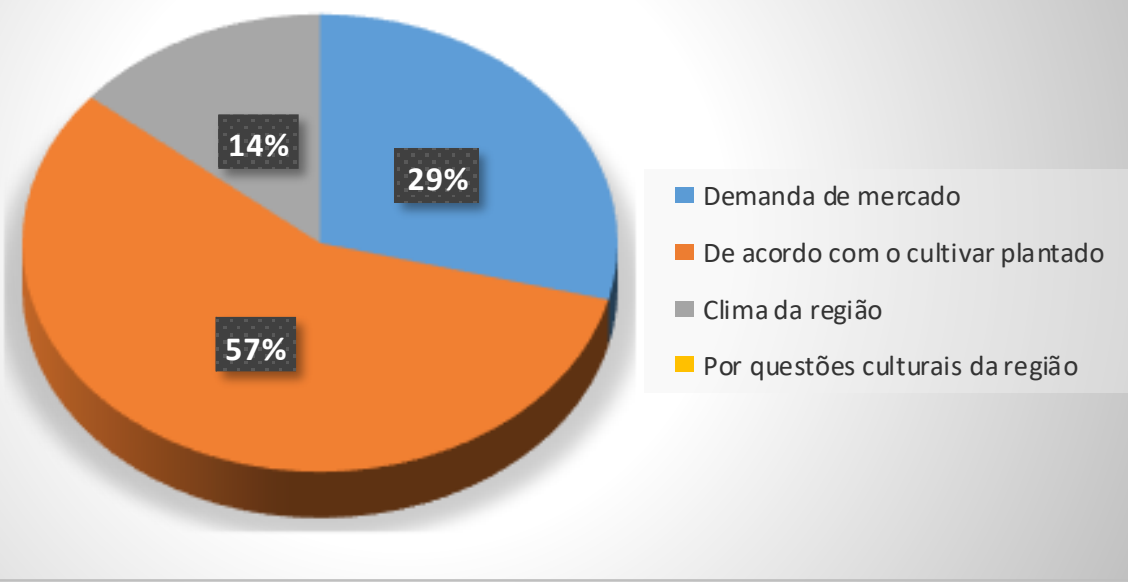

Fonte: Dados da pesquisa (2020)

No gráfico 3, evidencia-se que processo de tomada de decisão, em relação ao período que o cultivar deve ser produzido, está associado ao cultivar que será plantado (57\%), outros $29 \%$ alinham-se a demanda do mercado, que está associado ao consumo de diferentes produtos a estações do ano.

Apresentados os períodos de produção adotados pelos participantes da pesquisa, passou-se para etapa que merece bastante atenção por parte do produtor rural, que são os controles de atividades aplicado nas propriedades rurais, apresentados no gráfico 4, aspecto esse, importante para sucesso no exercício da atividade rural.

Gráfico 4: Tipos de controles das atividades que são realizados na propriedade rural

\section{Quais os controles de atividade que são realizados na sua propriedade}

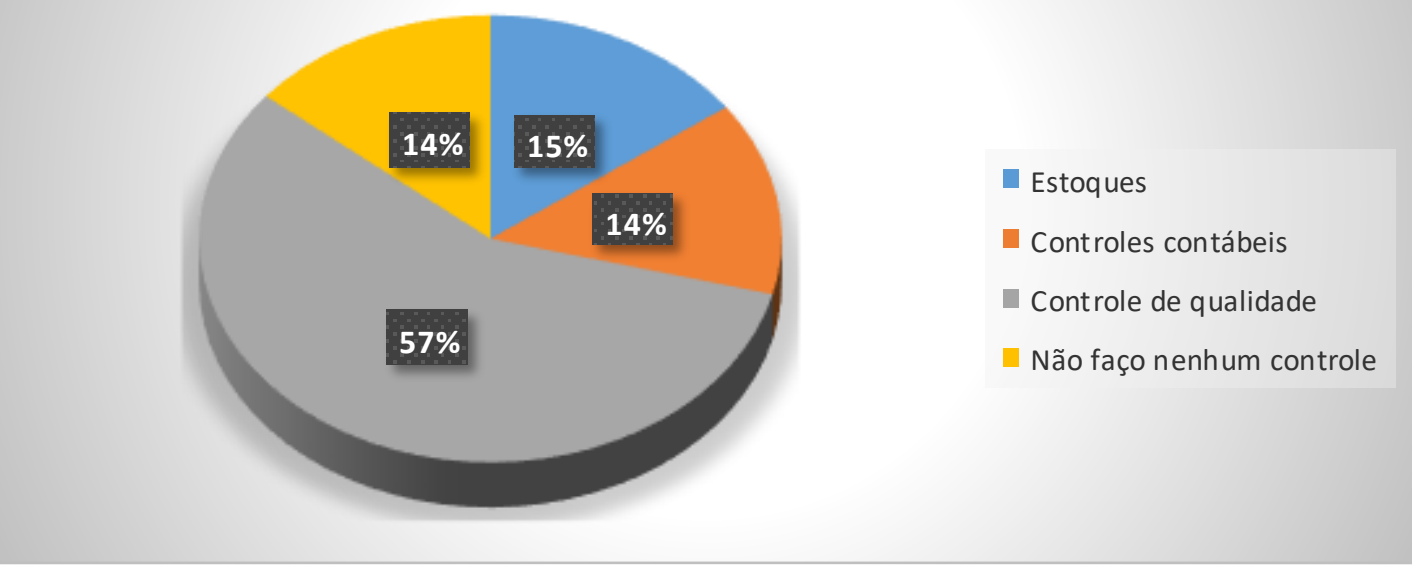

Fonte: Dados da pesquisa (2020) 
O gráfico 4 mostra que $57 \%$ dos produtores entrevistados estão preocupados com 0 controle de qualidade de sua produção, outros $15 \%$ realizam o controle dos estoques. Já aplicação de controle contábeis, aparece em 14 \% dos entrevistados, ou 14\% não fazem nem um tipo de controle. Mesmo os produtores, estando ciente da importância da aplicação de controle financeiro no exercício de suas atividades, índice ainda é baixo devido ao desconhecimento que os produtores têm sobre seu uso. Nesse sentido, Crepaldi (1998), destaca que para produtor rural ter sucesso em sua atividade rural, não basta apenas ela saber o que, quando e como produzir, nem disponibilizar subsídios financeiros para o fomento da atividade rural, sem que haja em paralelo uma preocupação com o controle e gerenciamento dos investimentos aplicados antes e durante a atividade (produção) e avaliar os resultados alcançados, comparando-os com o previsto inicialmente, com os obtidos em safras anteriores e com o resultado obtido por outros produtores.

Por fim, foi efetuada uma abordagem acerca do registro de atividades, na qual se questionou onde que são formalizados os registros das atividades exercidas na propriedade, conforme descrito no gráfico 5.

Gráfico 5: Local de registro das atividades

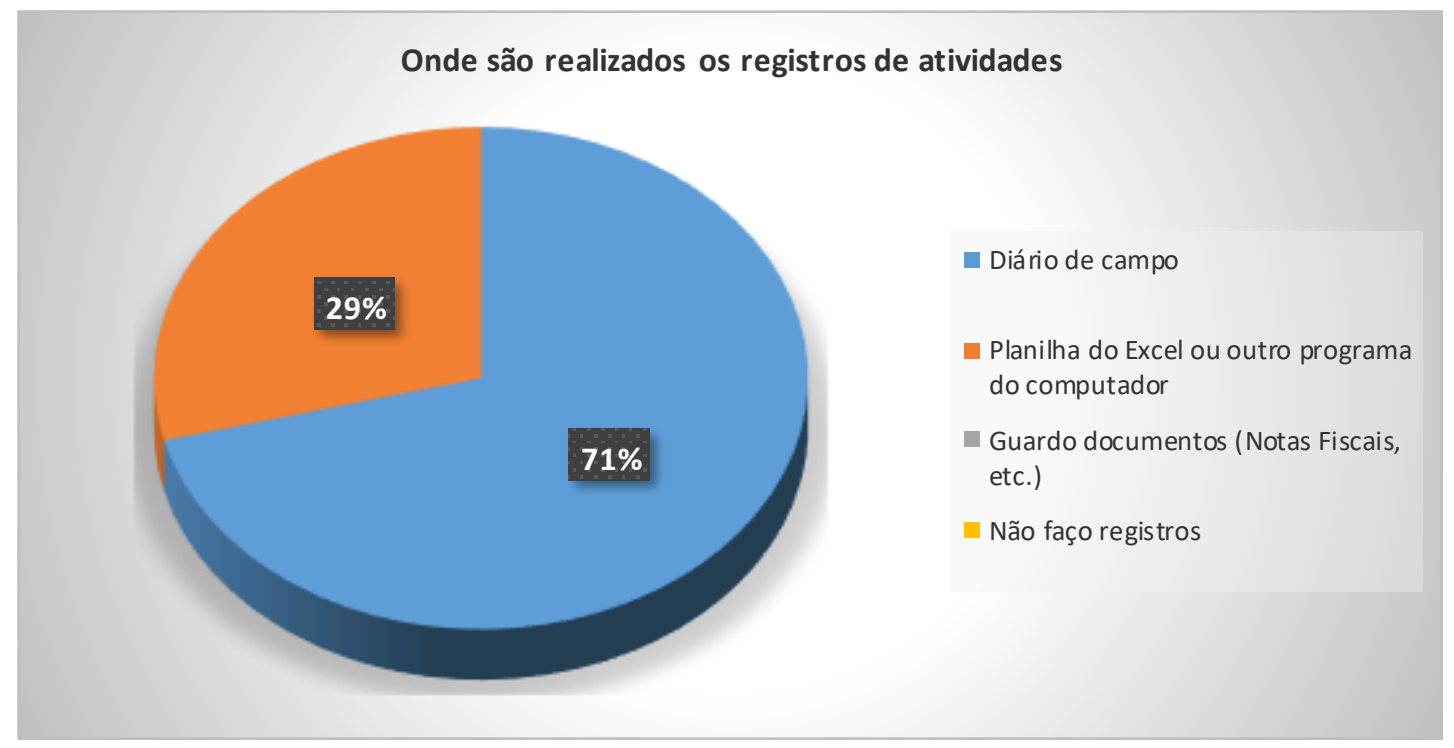

Fonte: Dados da pesquisa (2020)

Os resultados apresentados no gráfico 5 , mostram que $71 \%$ dos produtores rurais participantes dessa pesquisa, relataram que todos os registros de atividades são realizados no diário de campo, outros 29\%, usam planilha de Excel ou algum outro programa do computador. O uso do diário de campo, apresenta uma evolução no exercício das atividades exercidas no 
meio rural, mesmo sem analisar qualidade das informações transcritas, remete-se que os produtores, tem um histórico de sua produção para poder acompanhar exercício de suas atividades, auxiliando no processo de tomada de decisão.

\section{Considerações finais}

O presente estudo, teve por objetivo compreender como ocorre o processo de tomada de decisão, no tocante a gestão rural pelos associados da Coopasvale-RS, em contextos de desenvolvimento organizacional e regional. A partir do entendimento que a contabilidade e a gestão de custos se apresentam como ferramentas gerenciais que permitem, por meio de informações contábeis, o planejamento e o controle orçamentário.

A reflexão teórica sobre o tema envolveu o entendimento da multidimensionalidade de como acontece o processo de tomada de decisão na COOPASVALE-RS, ancorada na teoria de Herbert Simon, que destaca uma racionalidade limitada do indivíduo, que determina uma classificação de informações que podem ser relevantes, porém não faz uma análise de todos os dados disponíveis. Nessa senda o autor concluiu que o ser humano se utiliza de atalhos intitulados por ele de heurísticas, para realizar a tomada de decisão e enfrentar os obstáculos da vida real, como processos de observação e definição da pesquisa por alternativas de escolha (SIMON, 1990, apud SBICCA, 2014).

Essa concepção foi desenvolvida por meio da análise do processo de tomada de decisão na agricultura familiar, utilizada como chave para a difusão do conhecimento e como ponto de largada para a criação de estratégias que promovam o desenvolvimento da região. Esses instrumentos de execução integram-se a instâncias participativas da comunidade local, em particular a acadêmica, ampliando as margens de planejamento e reduzindo o grau de incerteza inerente ao funcionamento do processo de tomada de decisão.

Como principais resultados da pesquisa destacam-se que, $86 \%$ dos cooperados da COOPASVALE não tem dificuldade para definir qual cultivar será produzido em sua propriedade, essa escolha em $57 \%$ dos casos está associada a fatores econômicos. Resultados esse alinha-se a pesquisa realizada por Ocaña (1996), que associa o processo de tomada de decisão de agricultores, está fortemente alinhado a fatores socioeconômicos.

Dentre as diferentes variáveis, que estão associados ao processo de tomada de decisão na agricultura familiar, não se pode deixar de destacar a importância da aplicação de controles econômicos e financeiros nas propriedades, nesse caso, $14 \%$ dos participantes da pesquisa 
aplicam esse tipo de controle. Mesmo que estes, estejam cientes que está análise pode se tornar um tripé que embasa o processo de tomada de decisão, endossando a validação de outros fatores talvez não tão tangíveis. Desta forma, a pesquisa contribui com elementos que sugerem ser importantes para o processo de tomada de decisão, pois tais resultados trazem definições mais claras de como os aspectos econômicos interferem no processo de tomada de decisão dos associados da Coopasvale-RS.

Dentre as limitações desta pesquisa, destaca-se que a amostra selecionada poderia ser ampliada para reduzir a margem de erro que ficou em $9 \%$, porém o número de respondentes foi considerado satisfatória para os fins deste estudo. Salienta-se também que os resultados obtidos se restringem a realidade local no município de Passo do Sobrado- RS e faz com que não necessariamente estes sejam aplicáveis a outras regiões do Estado e do Brasil.

Em relação ao questionamento da pesquisa, observa-se que processo de tomada de decisão dos associados da Coopasvale-RS, está associado principalmente a fatores inerentes a economia da região onde residem seus associados. A não aplicação de controles econômicos e financeiros na maioria das propriedades dos cooperados reforçam esse entendimento.

\section{Referências}

Agências de alimentação da ONU lançarão em maio Década para a Agricultura Familiar. Nações Unidas Brasil, 2019. Disponível em: <https://nacoesunidas.org/agencias-de-alimentacao-daonu-lancarao-em-maio-decada-para-a-agricultura-familiar/>. Acesso em: 10 de Mar. de 2020.

BATALHA, Mário Otávio; BUAINAIN, Antônio Márcio; SOUZA FILHO, HM de. Tecnologia de gestão e agricultura familiar. Gestão Integrada da Agricultura Familiar. São Carlos (Brasil): EDUFSCAR, p. 43-66, 2005.

BECK, U. A reinvenção da política: rumo a uma teoria da modernização reflexiva. In: BECK, U.; GIDDENS, A.; LASCH, S. Modernização reflexiva: política, tradição e estética na ordem social moderna. Tradução Magda Lopes. 2. ed. São Paulo: Edunesp, 2012.

BORNIA, Antonio Cezar. Análise Gerencial de Custos - Aplicação em Empresas Modernas. 3 ed. São Paulo : Atlas , 2010. p. 02-17.

CAMPOS, Mariana; VILLAR, Rosana. Agricultura familiar, a solução para os nossos pepinos. Greenpeace, 2019. Disponível em: <https://www.greenpeace.org/brasil/blog/agriculturafamiliar-a-solucao-para-os-nossos-pepinos/?gclid=EAlalQobChMI3vT-v_rb6AIVjQRCh274gCyEAAYASAAEgl-a_D_BwE>. Acesso em: 05 de Mar. de 2020.

CALLADO, A. L. C; ALBUQUERQUE, J. de L. ; SILVA, A. M. N. da. Análise da relação custo/volume/lucro na agricultura familiar: o caso do consórcio mamona/feijão. Custos e Agronegócios on line, v. 3, n. 1, jan/jun. 2007.

CREPALDI, S. A. Contabilidade geral: uma abordagem decisorial. 2. ed. São Paulo: Atlas, 1998. 
DA ROSA, Nadir Paula et al. Fatores influentes no processo decisório de agricultores de produtos orgânicos. Desenvolvimento Socioeconômico em Debate, v. 4, n. 1, p. 60-87, 2018.

DEPONTI, Cidonea Machado. As" Agruras" da gestão da propriedade rural pela agricultura familiar. Redes (St. Cruz Sul, Online), v. 19, n. 2014, p. 9-24, 2014.

DURÁN, C. A.; WIVES, D. G. Decision making and agriculture: a recent review of organic farming. Desenvolvimento em Questão, v. 16, n. 43, p. 175-199, 2018.

ETGES, Virginia Elisabeta; DEGRANDI, José Odim. Desenvolvimento regional: a diversidade regional como potencialidade. Revista Brasileira de Desenvolvimento Regional, v. 1, n. 1, p. 085094, 2013.

FONSECA, Maria Helena da et al. Gestão de custos na agricultura familiar na cidade de Ponta Grossa. 2018. Dissertação de Mestrado. Universidade Tecnológica Federal do Paraná.

FONTOURA, Fernando Batista Bandeira da; DEPONTI, Cidonea Machado. Desenvolvimento rural: a importância das TICS e dos controles econômicos e financeiros na visão dos agricultores familiares do Vale do Caí-RS. Revista Brasileira de Planejamento e Desenvolvimento, v. 7, n. 1, p. 85-103, 2018.

FONTOURA, Fernando Batista Bandeira. Gestão de Custos: Uma Visão Integrada e Prática dos Métodos de Custeio. 1. ed. São Paulo: Atlas, 2013.

GURA, Andréia et al. Gestão de custos: práticas utilizadas em propriedades rurais familiares. 2018. Dissertação de Mestrado. Universidade Tecnológica Federal do Paraná.

KARNOPP, E. Tendências de desenvolvimento da agricultura familiar: uma análise regional. RDE-Revista de Desenvolvimento Econômico, v. 14, n. 26, 2012.

LAVADO, Thiago. Uso da internet no Brasil cresce, e 70\% da população está conectada. G1 Economia, 2019. Disponível em:

<https://g1.globo.com/economia/tecnologia/noticia/2019/08/28/uso-da-internet-no-brasilcresce-e-70percent-da-populacao-esta-conectada.ghtml>. Acesso em: 10 de Mar. de 2020.

MARTINS, E.; ROCHA, W. Métodos de custeio comparados: custos e margens analisadas sob diferentes perspectivas. 2.ed. São Paulo: Atlas, 2015.

Município de Passo do Sobrado. Cidade Brasil, 2019. Disponível em:<https://www.cidadebrasil.com.br/municipio-passo-do-sobrado.html> Acesso em: 02 de mar. de 2020.

OLIVEIRA, Kamila Pagel de; DE PAULA, Ana Paula Paes. Herbert Simon e os limites do critério de eficiência na nova administração pública. Cadernos Gestão Pública e Cidadania, v. 19, n. 64, 2014.

OLIVEIRA, L. M. A informação como instrumento para tomada de decisão do agricultor de Giruá no Estado do Rio Grande do Sul-Brasil. 2007. Dissertação (Programa de Pós-Graduação em Agronegócios - Mestrado), Universidade Federal do Rio Grande do Sul, Porto Alegre, 2007.

Passo do Sobrado. IBGE, 2010. Disponível em: <https://cidades.ibge.gov.br/brasil/rs/passo-dosobrado/panorama>. Acesso em: 02 de Mar. de 2020.

Passo do Sobrado. Turismo RS, 2020. Disponível em:

<https://www.turismo.rs.gov.br/cidade/237/passo-do-sobrado>. Acesso em 02 de Mar. de 2020.

PEREIRA, V.; BRITO, T.; PEREIRA, S. A feira-livre como importante mercado para a agricultura familiar em Conceição do Mato Dentro (MG). Revista Ciências Humanas, v. 10, n. 2, 2017. 
RAMBO, Anelise Graciele., MACHADO, João Armando Dessimon. Tomada de decisão em questões relativas ao desenvolvimento territorial: capital social, empoderamento e governança na agricultura familiar. In: CONGRESSOS DA SOCIEDADE BRASILEIRA DE ECONOMIA, ADMINISTRAÇÃO E SOCIOLOGIA RURAL, 47., 2009, Porto Alegre. Anais... Porto Alegre, RS: SOBER, 2009. p. 1-20. 1CD-ROM. RAMOS, G. Un acercamiento teórico.

RODRÍGUEZ OCAÑA, A. Propuesta metodológica para el análisis de la toma de decisiones de los agricultores: aplicación al caso del regadío extensivo cordobés. 1996. 221 f. Tese (Doutorado em Economia Agroalimentar) - Universidade de Córdoba, Córdoba, Espanha, 1996.

RODRíGUEZ OCAÑA, A. VECINO, B. J.; AVILÉS, R. P. Metodología para el análisis de la toma de decisiones de los agricultores. Madrid: INIA, 1998.

SANTOS, M. Sociedade e espaço: a formação social como teoria e método. Petrópolis: Vozes, 1982.

SBICCA, Adriana. Heurísticas no estudo das decisões econômicas: contribuições de Herbert Simon, Daniel Kahneman e Amos Tversky. Estudos Econômicos (São Paulo), v. 44, n. 3, p. 579603, 2014.

SALES, Rafaela. O Processo Decisório nas Organizações. Portal Administração, 2020. Disponível em: < https://www.portal-administracao.com/2014/03/o-processo-decisorio-nasorganizacoes.html>. Acesso em: 27 de Mai. de 2020.

SILVEIRA, Denise Tolfo; CÓRDOVA, Fernanda Peixoto. Unidade 2-A pesquisa científica. Métodos de pesquisa, v. 1, 2009.

SILVA, Antonio Carlos Ribeiro da. Metodologia da pesquisa aplicada à contabilidade. Salvador, BA: UFBA, Faculdade de Ciências Contábeis, Superintendência de Educação a Distância, 2017. 173 p. ISBN 9788582921067 (broch.). Disponível em:

<https://repositorio.ufba.br/ri/handle/ri/24428>. Acesso em: 11 Mai. 2020.

SIMON, Herbert A. A capacidade de decisão e de liderança. Rio de Janeiro: Fundo de Cultura, 1972.

SIMON, Herbert. Rationality as process and as product of thought. American Economic. Review, v. 68, n. 2, p. 1-16, 1978.

SOCIEDADE NACIONAL DA AGRICULTURA (SNA). Mundo volta suas atenções para a agricultura familiar. 2014. Disponível em: < https://www.sna.agr.br/mundo-volta-suas-atencoes-para-aagricultura-familiar/>. Acesso em: 13 Abr. 2020.

STEINGRABER, Ronivaldo; FERNANDEZ, Ramon Garcia. A racionalidade limitada de Herbert Simon na Microeconomia. Revista da Sociedade Brasileira de Economia Política, 2013.

STEINGRABER, Ronivaldo; FERNANDEZ, Ramon Garcia. A racionalidade limitada de Herbert Simon na Microeconomia. Revista da Sociedade Brasileira de Economia Política, 2013.

TENÓRIO, G. F. A unidade dos contrários: fordismo e pós-fordismo. Rio de Janeiro: RAP, 2011.

TENÓRIO, G. F. Gestão social: uma perspectiva conceitual. Rio de Janeiro, RAP, set./out., 1998. 